\title{
Goji Berry (Lycium Barbarum) in the treatment of diabetes mellitus: a systematic review
}

\author{
${ }^{1}$ Silva, C.S., ${ }^{1}$ Alves, B.C.A., ${ }^{2}$ Azzalis, L.A., ${ }^{2}$ Junqueira, V.B.C., ${ }^{3}$ Fonseca, R., ${ }^{1}$ Fonseca, \\ A.L.A. and ${ }^{1,2^{*}}$ Fonseca, F.L.A. \\ ${ }^{1}$ Laboratório de Análises Clínicas da Faculdade de Medicina do ABC, Av. Príncipe de Gales, 821, CEP \\ 09060-650,Santo André, SP, Brasil \\ ${ }^{2}$ Instituto de Ciências Farmacêuticas, Universidade Federal de São Paulo, Rua Prof. Artur Riedel, 275, \\ CEP 09972-270, Diadema, SP, Brasil \\ ${ }^{3}$ Serviço de Pediatria do Hospital Sírio Libanês, Rua Dona Adma Jafet, 91, CEP 01308-050, São Paulo, \\ SP, Brasil
}

\begin{abstract}
Article history:
Received: 14 June 2017

Received in revised form: 18 July 2017

Accepted: 19 July 2017

Available Online: 19 July 2017
\end{abstract}

\section{Keywords:}

Diabetes Mellitus,

Goji Berry (Lycium

barbarum),

Systematic review

DOI:

http://doi.org/10.26656/ fr.2017.6.102

\begin{abstract}
Diabetes Mellitus (DM) is a chronic disease characterized by disorders in the metabolism of carbohydrates, lipids, lipoproteins and increased oxidative stress. New therapeutic alternatives have been studied for the treatment of DM and due to their antioxidant content, the Goji Berry is being widely used as a functional food. We performed a systematic review on the use of Goji Berry (Lycium barbarum) for the DM treatment. A systematic review was conducted through the PUBMED and LILACS databases being used the terms "Goji Berry and Diabetes", "Lycium Barbarum and Diabetes", "Goji Berry and Diabetes and Treatment" and "Lycium Barbarum and Diabetes and Treatment". Results showed Goji Berry (Lycium barbarum) has the potential to be effective in the treatment DM. Goji Berry would be an excellent alternative to already currently available drugs and contain no adverse effects. So, it is extremely important that more research on the subject to support its importance.
\end{abstract}

\section{Introduction}

Diabetes Mellitus (DM) is a chronic disease characterized by disorders in the metabolism of carbohydrates, lipids, lipoproteins, and increased oxidative stress. It is classified as diabetes mellitus type I (DMI), when there is a destruction of pancreatic beta cells and the patient becomes insulin dependent, as there is a deficiency in insulin secretion, and diabetes mellitus type II (DMII) characterized by problems in secretion and action of insulin pump, with the latter mainly associated with lifestyle and morbidities such as obesity, dyslipidemia and hypertension (Luo et al., 2004; Singh et al., 2013; Hadi et al., 2015; SBD, 2015).

It is predicted that by 2035 this condition affects around 471 million people, due to growth and aging of the population, concomitant poor diet, and sedentary lifestyle. Besides the physical and psychological damage to those facing this disease, DM is also the cause of the budget increase in the Unified Health System (SUS), since Brazil had an average expenditure of $\$ 3.9$ billion to treat it (Wild et al., 2004; SBD, 2015).

Eating habits for patients with DM are essential for improvement in the individuals' life quality and preventing the disease future complications and its associated morbidity. Drug treatment is inevitable, although in many cases bring many adverse effects like weight gain, hypoglycemia, gastrointestinal symptoms among others (Singh et al., 2013; George and Joseph, 2014; SBD, 2015).

New therapeutic alternatives are being studied for the treatment DM. As a cheaper alternative with fewer adverse effects to these carriers, the Goji Berry (Lycium Barbarum, from Solanaceae family) is being widely used as a functional food, mainly for their antioxidant action due to a high content of vitamin C. Experiments have shown its effectiveness in aging, increased metabolism, immune system, liver function and glycemic control. However, their benefits are attributed to the bioactive 
component polysaccharide-protein complex 4 (LBP4), which is composed of six monosaccharides (galactose, glucose, rhmnose, arabinose, mannoseandxylose) (Amagase and Nance, 2008; Ming et al., 2009; Amagase et al., 2009; Lu and Zhao, 2010; Carnés et al., 2013).

The objective of this study was to perform a systematic review on the use of Goji Berry (Lycium barbarum) for the diabetes mellitus (DM) treatment.

\section{Methodology}

A systematic review was conducted through the PUBMED and LILACS databases being used the terms "Goji Berry and Diabetes", "Lycium Barbarum and Diabetes", "Goji Berry and Diabetes and Treatment" and "Lycium Barbarum and Diabetes and Treatment" from January 2006 until July 2016. Because of the limited number of available scientific articles that fulfill the inclusion criteria a meta-analysis was not feasible for the preparation of this study.

The terms that have been used to the inclusion: (I) Such as available articles online (II) Articles in English (III) Original work (IV) Studies in humans or experimental. Exclusion criteria also included: (I) Review work (II) Items that were not in English (III) Treatment with other medicinal herbs associated with the Goji Berry (Lycium Barbarum), IV) Articles $>10$ years of publication. After the selection of potential all articles were read in full and tabulated containing article (author's name and year of publication), the journal in which it was published, population, study time and main results.

\section{Results}

At first, a total of 35 articles about the subject was found. After analyzing the titles and performing an advanced research, 21 articles were considered, but when read in its total by applying the inclusion and exclusion criteria (Figure 1), only six articles fulfilled the criteria previously established in this study (Table 1).

\section{Discussion}

Diabetes Mellitus is a chronic disease characterized by disorders in the metabolism of carbohydrates, lipids, lipoproteins, and increased oxidative stress and eating habits for patients with DM are essential for improvement in the individuals' life quality and preventing the disease future complications and its associated morbidity. Although drug treatment is inevitable, an alternative with fewer adverse effects to these drugs is the Goji Berry (Lycium Barbarum). The bioactive component LBP-4 has been the target of several studies for its anti-hypoglycemic role and because of its antioxidants role. Zhao et al. (2014) conducted a study to analyze insulin resistance through translocation and activation of GLUT4. This study suggests that LBP-4 had a moderate glucose action in OLETF rats and may improve glucose intolerance, thereby favoring insulin resistance, having a greater increase in the translocation of GLUT4 by LBP-4 than for insulin, plus a GLUT4 exposure increment in adipocytes by LPB-4, raising the hypothesis that insulin resistance progress is due to these two factors (Zhao et al., 2014).

The efficacy of Goji berries for DMII patients was shown by Cai et al. (2015). In this study, Goji berry was administered for 3 months twice daily in capsules of 300 $\mathrm{mg}$ with LBP-4 to diabetic type II patients. According to the authors, improvements in post prandial serum glucose levels and the increase of HDL in these subjects, as well as a decrease level of TNF- $\alpha$, were observed. These results were more successful in patients who did not use anti hypoglycemic drugs.

After using Goji berry in diabetic nephropathy, Zhao et al. (2009) observed that there was a decrease in proteinuria and a significant improvement in other renal markers, thus decreasing renal injury in rats.

Another positive finding regarding the use of Goji berry was found by Jing et al. (2009). According to the authors, the use of LBP-4 in diabetic rats showed a decrease in total cholesterol and triglycerides levels. Li (2007) showed in his research that LBP restored the levels of lipid peroxidation, thereby reducing blood glucose rates, which may be associated with the use of LBP for improving lipid disorders in diabetic rats addition to delaying the onset of diabetes.

In a new study using diabetic rabbits induced by Alloxan, Zhao et al. (2016) showed that the recommended dosage for the beneficial effect of LBP is $10 \mathrm{mg} / \mathrm{kg}$, different from the amounts in studies previously reported. The effect of LBP was compared in five groups of rabbits: group I, non-diabetic group; group II, diabetic nephropathy control (DN) treated with placebo; group III, held the exclusive use of LBP in diabetic rabbits (DM) with the objective to prevent; group IV, using the Telmisartan drug for improvement of $\mathrm{DN}$ and the group V, using the LBP (10 $\mathrm{mg} / \mathrm{kg}$ in $3 \mathrm{ml})$ as a treatment in DN. At the end of the experiment the LBP treatment group (V), when compared to the $\mathrm{DN}$ 


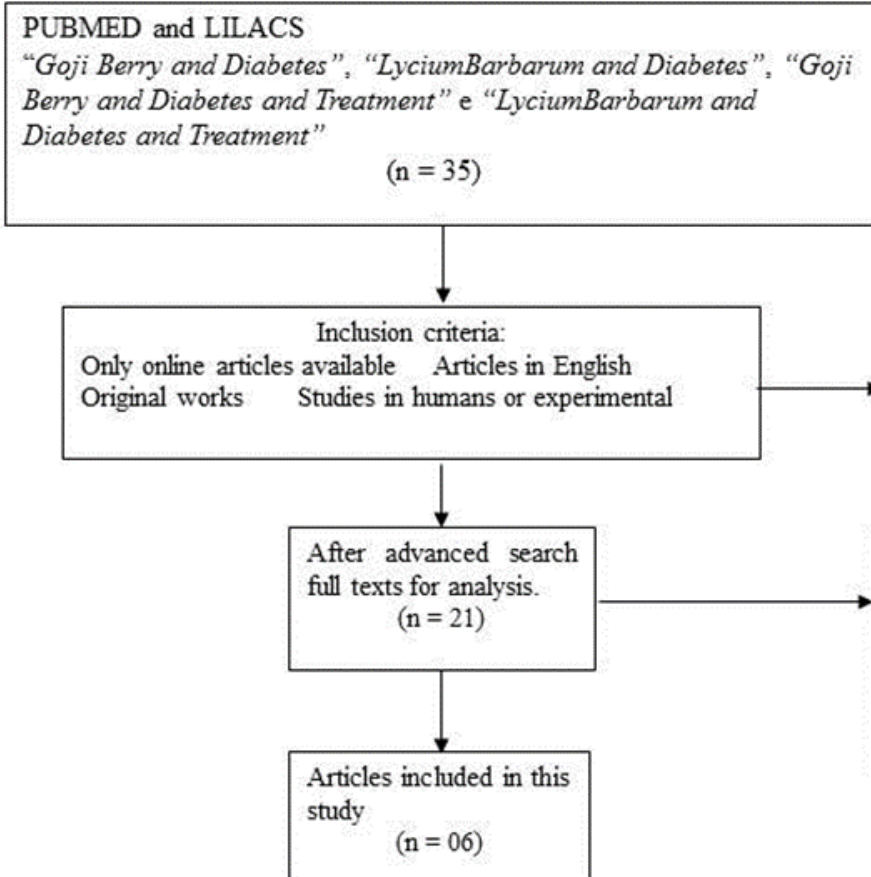

(35) excluded References

a) Articles not in English

b) Articles not available in full

c) Case Study

d) Review of Literature

e) Articles not related to diabetes

(21) Full papers excluded reasons

a) Articles on physical-chemical analysis of the plant.

b) Studies without exclusive use of Goji

Berry (Lycium Barbarum).

c) Articles not related to diabetes

d) Publication Year $>10$ years)

Figure 1. Selection Process articles eligible for the study.

Table 1. General characteristics of the articles included in the study.

\begin{tabular}{|c|c|c|c|c|}
\hline Article & Journal & Population & Study Time & Main results \\
\hline $\begin{array}{l}\text { Zhao et al. } \\
\text { (2014) }\end{array}$ & $\begin{array}{l}\text { Food and } \\
\text { Function }\end{array}$ & 18 male OLETF rats & 04 weeks & $\begin{array}{l}\text { Showed an improvement of insulin resistance } \\
\text { through the translocation of GLUT4. }\end{array}$ \\
\hline $\begin{array}{l}\text { Cai et al. } \\
(2015)\end{array}$ & $\begin{array}{l}\text { Medical } \\
\text { Chemistry }\end{array}$ & 67 patients DM II & $\begin{array}{l}03 \\
\text { consecutives } \\
\text { months }\end{array}$ & $\begin{array}{l}\text { There was an increase of HDL and the most } \\
\text { effective hypoglycemic effect was who did not } \\
\text { use drugs. }\end{array}$ \\
\hline $\begin{array}{l}\text { Zhao et al. } \\
\text { (2009) }\end{array}$ & $\begin{array}{c}\text { Journal of } \\
\text { Physiology and } \\
\text { Pharmacology }\end{array}$ & $\begin{array}{l}\text { 32male Wistar rats } \\
\text { (streptozotocin- } \\
\text { induced diabetes } \\
\text { STZ) }\end{array}$ & 08 weeks & $\begin{array}{l}\text { LPB-4 possesses protective properties in } \\
\text { patients with diabetic nephropathy. }\end{array}$ \\
\hline $\begin{array}{l}\text { Jing et al. } \\
\text { (2009) }\end{array}$ & $\begin{array}{l}\text { African Journal } \\
\text { of Traditional, } \\
\text { Complementary } \\
\text { and Alternative } \\
\text { Medicines }\end{array}$ & $\begin{array}{l}40 \text { male rats } \\
\text { (Diabetes induced by } \\
\text { Alloxan) }\end{array}$ & 28 days & $\begin{array}{l}\text { The use of } 40 \mathrm{mg} \text { was more effective in rats } \\
\text { than the dose of } 20 \mathrm{mg} \text {, demonstrating Goji } \\
\text { berry having potential for the treatment of } \\
\text { diabetes, besides not being shown hepatotoxic } \\
\text { effect. }\end{array}$ \\
\hline Li (2007) & $\begin{array}{l}\text { International } \\
\text { Journal of } \\
\text { Biological } \\
\text { Macromolecular } \\
\text { es }\end{array}$ & $\begin{array}{l}50 \text { Wistar rats } \\
\text { (streptozotocin- } \\
\text { induced diabetes } \\
\quad \text { STZ) }\end{array}$ & 30 days & $\begin{array}{l}\text { It is suggested that LBP can be used as anti- } \\
\text { hypoglycemic agent in addition to its } \\
\text { protective effect on the kidneys and liver, } \\
\text { because of its antioxidants. }\end{array}$ \\
\hline $\begin{array}{l}\text { Zhao et al. } \\
\qquad(2016)\end{array}$ & Life Sciences & $\begin{array}{l}25 \text { Japonese male } \\
\text { rabbits (Diabetes } \\
\text { induced by Alloxan) }\end{array}$ & 12 weeks & $\begin{array}{l}\text { Using the LBP an improvement in renal } \\
\text { function and inflammation in diabetic rabbits, } \\
\text { but the effect was more effective in preventing } \\
\text { rather than the treatment of this pathology. }\end{array}$ \\
\hline
\end{tabular}

group (II), showed an improvement in fasting glucose tolerance; group prevention (III), when compared to treatment group with LBP (V), showed better results, and its use was more feasible for prevention of kidney issues caused by diabetes.

By analyzing the articles described in this study, we can see that various methodologies were used to prove the utility of Goji berry. Thus, it is difficult to standardize a single method, which would be beneficial to achieve more reliable results. Research has demonstrated that the Goji berry (Lycium barbarum) has the potential to be effective in the treatment DM, in addition to its protective effect on renal disease patients and their high antioxidant effect. Therefore it is extremely important more research on the subject to support its importance, as this would be an excellent alternative to already currently available drugs.

\section{Conflict of Interest}

No competing financial interests exist. 


\section{References}

Amagase, H. and Nance, D.M. (2008). A randomized, double-blind, placebocontrolled, clinical study of the general effects of a standardized Lycium barbarum (Goji) Juice, GoChi. Journal of Alternative and Complementary Medicine, 14, 403-412.

Amagase, H., Sun, B. and Borek, C. (2009). Lycium barbarum (goji) juice improves in vivo antioxidant biomarkers in serum of health adults. Nutrition Research, 29, 19-25.

Cai, H., Liu, F., Zuo, P., Huang, G., Song, Z., Wang, T., Lu, H., Guo, F., Han, C. and Sun, G. (2015). Practical application of antidiabetic efficacy of Lycium barbarum Polysaccharides in patients with type 2 Diabetes. Medical Chemistry, 11, 383-390.

Carnés, J., Larramendi, C.H., Ferrer, A., Huertas, A.J., López-Matas, M.A., Pagán, J. A., Navarro, L.A. and García-Abujeta, J.L. (2013). Recently introduced foods as new allergenic sources: Sensitisation to Goji berries (Lycium barbarum). Food Chemistry, 137, 130-135.

George, R.E. and Joseph, S. (2014). review of newer treatment approaches for ty pe-2 diabetes: Focusing safety and efficacy of incretin based therapy. Saudi Pharmaceutical Journal, 22, 403-401.

Hadi, N.R., Abdelhussein, M.A., Rudha, A.R.M., Jamil, D.A. and Al-Aubaidy, H.A. (2015). Simvastatin Use in Patients with Type 2 Diabetes Mellitus: The Effects on Oxidative Stress. Oman Medical Journal, 30, 237-240.

Jing, L., Cui, G., Feng, Q. and Xiao, Y. (2009). Evaluation of the hypoglycemic activity of the polysaccharides extracted from Lycium barbarum. African Journal of Traditional, Complementary and Alternative Medicines, 6, 579-584.

Li, X.M. (2007). Protective effect of Lycium barbarum polysaccharides on streptozotocin- induced oxidative stress in rats. International Journal of Biological Macromolecules, 40, 461-465.

Lu, S.P. and Zhao, P.T. (2010). Chemical characterization of Lycium barbarum polysaccharides and their reducing myocardial injury in ischemia/ reperfusion of rat heart. International Journal of Biological Macromolecules, 47, 681-684.

Luo, Q., Cai, Y., Yan, J., Sun, M. and Corke, H. (2004). Hypoglycemic and hypolipidemic effects and antioxidant activity of fruit extracts from Lycium barbarum. Life Sciences, 76, 137-139.

Ming, M., Guanhua, L., Zhanhai, Y., Guang, C. and Xuan, Z. (2009). Effect of the Lycium barbarum polysaccharides administration on blood lipid metabolism and oxidative stress of mice fed high-fat diet in vivo. Food Chemistry, 113, 872-877.

Singh, R., Kaur, N., Kishore, L. and Gupta, G.K. (2013). Management of Diabetic complications: A chemical constituents based approach. Journal of Ethnopharmacology, 150, 51-70.

Sociedade Brasileira de Diabetes (SBD). (2015). Diretrizes da Sociedade Brasileira de Diabetes: 2014 -2015 [organização José Egidio Paulo de Oliveira, Sérgio Vencio]. São Paulo: AC Farmacêutica

Wild, S., Roglic, G., Green, A., Sicree, R. and King, H. (2004). Global Prevalence of Diabetes: Estimates for the year 2000 and projections for 2030. Diabetes Care, 27, 1047-1053.

Zhao ,R., Li, Q.W., Li, J. and Zhang, T. (2009). Protective effect of Lycium barbarum polysaccharide 4 on kidneys in streptozotocin- induced diabetic rats. Canadian Journal of Physiology and Pharmacology, 87, 711-719.

Zhao, R., Qiu, B., Li, Q., Zhang, T., Zhao, H., Chen, Z., Cai, Y., Ruan, H., Ge, W. and Zheng, X. (2014). LBP-4a improves insulin resistance via translocation and activation of GLUT4 in OLETF rats. Food and Function, 5, 811-820.

Zhao, Q., Li, J., Yan, J., Liu, S., Guo, Y., Chen, D. and Luo, Q. (2016). Lycium barbarum polysaccharides ameliorates renal injury and inflammatory reaction in alloxan - induced diabetic nephoropathy rabbits. Life Sciences, 157, 82-90. 